\title{
Novel Pattern of P53 Mutation in Breast Cancers from Austrian Women
}

\author{
Arndt Hartmann, * Georg Rosanelli," Hagen Blaszyk, * Julie M. Cunningham, * Renee M. McGovern, * \\ Jennifer J. Schroeder, ${ }^{\star}$ Daniel J. Schaid, $\$$ John S. Kovach, ${ }^{*}$ and Steve S. Sommer* \\ *Departments of Oncology, ${ }^{\ddagger}$ Biochemistry and Molecular Biology, ${ }^{8}$ Health Sciences Research, Mayo Clinic and Mayo Foundation, \\ Rochester, Minnesota 55905; and "Department of Surgery, University of Graz, Austria
}

\begin{abstract}
Since mutagens produce an extraordinary diversity of mutational patterns, differential mutational exposures among populations are expected to produce different patterns of mutation. Classical epidemiological methods have been successful in implicating specific mutagens in cancers such as those of lung and skin in which one mutagen predominates. In breast cancer, however, no mutagens have been implicated in an unequivocal manner. In an attempt to facilitate epidemiological studies, we have been studying the pattern of $\mathbf{p 3}$ gene mutations in breast cancers from multiple populations with high and low breast cancer incidences. We previously reported that breast cancers from Midwest United States, predominantly rural Caucasian women, have a different pattern of p53 gene mutation from populations of Western European women. Herein, we analyze patterns of p53 mutations from Graz, Austria, another population with a high incidence of breast cancer. Among the 60 Austrian breast cancers analyzed, 14 (23\%) have a p53 gene mutation in exons 5-9 or in adjacent splice junctions. Analysis of the patterns of mutation shows differences between the "Western European" profile and the Austrian and Midwest United States groups $(P=0.027$ and 0.024 , respectively $)$. The Austrian pattern is characterized by a high frequency of $A: T \rightarrow T: A$ transversions $(P=0.006)$. The presence of distinct patterns of mutation among the limited number of analyzed populations of Western European origin supports the idea that differential mutagenic exposure and/or genetic differences contribute to breast cancer mutagenesis among geographically distinct Caucasians of Western European origin. (J. Clin. Invest. 1995. 95:686-689.) Key words: breast cancer $\cdot$ mutation $\bullet$ p53 gene $\cdot$ mutagens $\cdot$ Austria
\end{abstract}

\section{Introduction}

The pattern of acquired mutations in identical regions of a given gene in the same cancer type offers the possibility of detecting differences in mutagenic processes in different populations ( 1 , $2,3)$. The mutational pattern in the p53 gene is a particularly useful epidemiological tool for exploring mechanisms of mutagenesis because this gene is altered frequently in nearly all types of human cancers (reviewed in reference 4 ). Differences in

Address correspondence to Steve S. Sommer, M.D., Ph.D. Department of Biochemistry and Molecular Biology, Mayo Clinic, Rochester, MN 55905. Phone: 507-284-6033; FAX: 507-284-3383.

Received for publication 1 August 1994 and in revised form 10 October 1994.

The Journal of Clinical Investigation, Inc.

Volume 95, February 1995, 686-689 mutational patterns of the p53 gene may reflect the effects of specific carcinogens, for example the relationships between $\mathrm{G} \rightarrow \mathrm{T}$ transversions, cigarette smoke mutagens, and lung cancer (5); $\mathrm{G} \rightarrow \mathrm{T}$ transversions in codon 249 , aflatoxin $B_{1}$ exposure and hepatocellular carcinoma $(6,7)$; and $\mathrm{CC} \rightarrow \mathrm{TT}$ tandem dipyrimidine transitions, UV-B radiation, and squamous and basal cell carcinomas of the skin $(8,9)$.

We are studying patterns of p53 gene mutation in breast cancers of populations at different risk for this disease to look for evidence that different environmental or endogenous factors contribute to mammary carcinogenesis to different extents ( 10 , 11). In breast cancer the frequency of the disease varies more then fivefold between low-risk groups like Japanese women and high-risk populations like Caucasian women living in North America or Europe $(12,13)$. Immigration from a low-risk region (Japan) to a high risk region (California) substantially increases the frequency of disease (14-16), but no mutagens have been implicated in an unequivocal manner. We have shown that the pattern of p53 mutations in white, largely rural Midwestern U.S. women $(11,17)$ differs from the pattern in inner city African American women in Detroit, Michigan (18) and that reported in Scottish women (19). Herein, exons 5-9 of the p53 gene were analyzed in 60 primary breast cancers from the city of Graz, Austria.

\section{Methods}

Human tissue samples. 60 primary breast cancers collected consecutively by the Department of Surgery at Graz, Austria were analyzed. Written informed consent for these studies was obtained from the patients by $\mathrm{G}$. Rosanelli (Graz). These samples were snap frozen in liquid nitrogen, stored at $-70^{\circ} \mathrm{C}$, shipped to Rochester, Minnesota, on dry ice, and kept at $-70^{\circ} \mathrm{C}$ until analysis. The following clinical and biochemical data were provided from the Department of Surgery at Graz (G.R.): age, tumor stage, histological diagnosis, lymph node status, estrogen/ progesterone receptor (ER/PR $)^{1}$ status, DNA ploidy, and time of recurrence free survival. Samples were analyzed for $\mathrm{p} 53$ mutation by personnel without knowledge of these data.

Amplification and sequencing. Clusters of 50-100 tumor cells from touch preparations of the surface of partially thawed breast cancer tissue were used for the molecular analysis as described previously (10). Genomic amplification with transcript sequencing (GAWTS) was performed according to Stoflet et al. (20). PCR and sequencing primers for exons 5-9 and adjacent intronic regions were as described previously $(10,11)$. Exons 5-9 and adjacent intronic regions were screened for the presence of mutations by dideoxyfingerprinting (ddF). ddF is a hybrid of single stranded conformation polymorphism analysis (SSCP) and Sanger dideoxy sequencing. In ddF, a Sanger sequencing reaction is performed with only one of the four dideoxynucleotides. The sample is then electrophoresed on a nondenaturing gel. The presence of a mutation is detected by an abnormal migration pattern in any of the dideoxy

1. Abbreviations used in this paper: ddF, dideoxyfingerprinting; ER/ PR, estrogen/progesterone receptors. 
terminated segments containing the mutation and/or by an alteration in the number of segments. ddF detected 84 of 84 different types of point mutations in the factor IX gene (21). In an additional blinded comparison, ddF detected all 25 mutations in 73 breast cancers found by direct genomic sequencing of the p53 gene (Blaszyk, H., A. Hartmann, J. J. Schroeder, R. M. McGovern, S. S. Sommer, and J. S. Kovach, manuscript submitted for publication). Regions with abnormal ddF patterns were sequenced in both directions. The mutations found by direct sequencing were confirmed by reamplifying and resequencing the p53 gene segments from at least one additional cluster of tumor cells. Allelic status (hemi-, heterozygous) was judged on the basis of the presence or absence of wild-type sequence at the site of the mutation.

Immunohistochemistry. Clusters of tumors cells in touch preparations were stained for expression of p53 as described previously (10, 11). Briefly, the touch preparations were incubated with each of three p53 specific monoclonal antibodies (PAb1801, $0.5 \mu \mathrm{g} / \mathrm{ml}$, Cambridge Research Biochemicals [Cambridge, MA]; PAb240, $1 \mu \mathrm{g} / \mathrm{ml}$, Santa Cruz Biochemicals [Santa Cruz, CA] ; and PAb421, $1 \mu \mathrm{g} / \mathrm{ml}$, Oncogene Sciences Inc. [Manhasset, NY]). Bound antibody was detected with an avidin-biotin complex Elite kit (Vector Labs, Burlingame, CA) as directed by the manufacturer. Normal mouse IgG reagent was utilized as a negative control; tumor samples with p53 missense mutations which show strong nuclear staining with all three antibodies were used as positive controls. Tumors with $5 \%$ or more cells expressing p53 to any of the antibodies were considered immunohistochemically positive.

Statistical analysis. The patterns of mutation in exons 5-9 and adjacent splice regions in breast cancers of different ethnic groups were compared by the Fisher exact test using the StatXact software package (Cytel, Inc., Cambridge, MA). Time to progression was estimated by the method of Kaplan and Meier (22), and compared between women with a mutation versus women without a mutation by the exact logrank statistic (23). To adjust for the prognostic factors, ER, PR, and lymph node status, we performed a stratified log-rank statistic, stratifying on the prognostic factor.

\section{Results}

14 mutations (23.3\%) were found in exons 5-9 and adjacent intronic regions among the 60 Austrian breast cancers studied (Table I). This frequency of mutation is similar to the frequencies of p53 mutation in breast cancers of other European women (Table II). Only neoplastic cells were analyzed for mutations in the p53 gene. However, the vast majority of the detected mutations are presumed to be of somatic origin, because germline mutations in the p53 gene in women with breast cancer are rare even in a sample enriched for women with onset of the disease before age 35 or with a family history of breast cancer (24).

The three tumors with nonsense mutations or frameshift alterations did not express p53, whereas the only tumor with a splice site mutation (345T) did show nuclear immunoreactivity with all three antibodies (see Table I, asterisk). Of the 10 breast cancers with missense mutations, all but one expressed p53, detectable with at least two of the three antibodies used (Table I). The exception was a tumor with a $\mathrm{G}: \mathrm{C} \rightarrow \mathrm{A}: \mathrm{T}$ transition in codon 246 (tumor 347T) changing a methionine to isoleucine. This tumor may have a second p53 mutation outside exons 59, which might result in the absence of immunohistochemically detectable p53. However, we did not find any double mutation in 194 breast cancers sequenced in exons 2-11 of the p53 gene (Hartmann, A., H. Blaszyk, R. M. McGovern, J. J. Schroeder, J. Cunningham, E. M. G. DeVries, J. S. Kovach, and S. S. Sommer, manuscript submitted for publication).

For analysis of the mutational pattern, the mutations were classified into eight groups: deletions/insertions, G:C $\rightarrow \mathrm{A}: \mathrm{T}$ transitions at the dinucleotide $\mathrm{CpG}, \mathrm{G}: \mathrm{C} \rightarrow \mathrm{A}: \mathrm{T}$ transitions not at $\mathrm{CpG}, \mathrm{A}: \mathrm{T} \rightarrow \mathrm{G}: \mathrm{C}$ transitions, and the four types of transversions. No statistically significant strand bias was observed, although 5 of $7 \mathrm{C}: \mathrm{G} \rightarrow \mathrm{T}: A$ transitions were $\mathrm{G} \rightarrow \mathrm{A}$ changes in the sense strand. The pattern in the Austrian cohort was compared to the French, Icelandic, Norwegian and Scottish and our U.S. Caucasian groups and to a "European" profile consisting of the combined data for France, Scotland, Norway, and Iceland (Table II). Pairwise group analyses of the eight classes of mutation among the groups (Fisher Exact Test; $2 \times 8$ table - see Table II, footnotes) indicated an intergroup difference between the "Europeans" and the U.S. $(P=0.024)$ patients as well as a difference between the "Europeans" and the Austrians ( $P$ $=0.027$ ). The major intergroup differences were due to a higher frequency of A:T $\rightarrow \mathrm{T}: \mathrm{A}$ transversions in the Austrians ( $P$ $=0.006$ ) and an abundance of microdeletions in the U.S. whites $(P=0.012)$. The frequency of $\mathrm{A}: \mathrm{T} \rightarrow \mathrm{T}: \mathrm{A}$ transversions in the Austrian group is significantly higher than in the Icelandic ( $P$ $=0.04)$, Norwegian $(P=0.005)$ and Scottish $(P=0.03)$ but not in the French or U.S. groups.

Analysis of grade, stage, and type of carcinoma, DNA ploidy, age, and family history of the Austrian women did not reveal significant differences between those with and those without p53 mutations. Mutations were associated with low estrogen $(P=0.0001)$ and progesterone receptor (ER/PR) content $(P=0.0004)$. However, mutation, ER/PR status and lymph node status (involved or not involved) did not correlate with prognosis as assessed by disease free interval with a median duration of follow-up of 24 mos.

\section{Discussion}

Excess A:T $\rightarrow T: A$ transversions. Breast cancers from Austrian women have a different pattern of p53 gene mutation than breast cancers from other Caucasians of Western European origin. The most distinguishing feature of the pattern of mutation in the Austrian population is an excess of $\mathrm{A}: \mathrm{T} \rightarrow \mathrm{T}: \mathrm{A}$ transversions (4/ $14 ; 28.6 \%$ ). This difference is unlikely to be a technical artifact because: $(a)$ the pattern of mutation in breast cancer is not significantly affected by tumor stage or size (Hartmann, A., H. Blaszyk, J. Cunningham, R. M. McGovern, J. J. Schroeder, D. Schaid, J. S. Kovach, and S. S. Sommer, manuscript in preparation) so that differences in the ascertainment of patients with early cancers are unlikely to affect the observed patterns; and $(b)$ preferential detection of certain types of point mutations is not an issue since essentially $100 \%$ of mutations are detected by the methodology used (see Methods).

The basis for the observed excess of $\mathrm{A}: \mathrm{T} \rightarrow \mathrm{T}: \mathrm{A}$ transversions in the Austrian patients is not known. $A: T \rightarrow T: A$ transversions comprise less than $10 \%$ of all mutations reported in the p53 gene in human cancers including breast cancers from pooled populations (25) and less than $10 \%$ of all mutations in the factor IX gene (26). The pattern of mutation in the factor IX gene is similar across multiple ethnically and geographically diverse populations and is believed to reflect the endogenous (background) pattern of mutation in man (27). Thus, the threefold excess of $A: T \rightarrow T: A$ transversions in the Austrian group raises the possibility that there might be a factor contributing to mutagenesis that is more prevalent in that population. We are not aware of any epidemiological studies suggesting potential risk factors in the population of women residing in or near Graz/Austria. 


\begin{tabular}{|c|c|c|c|c|c|c|c|c|c|c|}
\hline \multirow{2}{*}{$\begin{array}{l}\text { Tumor } \\
\text { No. }\end{array}$} & \multirow[b]{2}{*}{ Age } & \multirow[b]{2}{*}{ Stage } & \multirow{2}{*}{$\begin{array}{l}\text { Exon/ } \\
\text { intron }\end{array}$} & \multirow[b]{2}{*}{ Nucleotide change } & \multirow[b]{2}{*}{ Structural change codon/A.A. } & \multicolumn{3}{|c|}{$\begin{array}{l}\text { Immunohistochemistry: } \\
\text { nuclear reactivity with } \\
\text { antibody }\end{array}$} & \multirow[b]{2}{*}{ Mutation type } & \multirow[b]{2}{*}{ Allelic status } \\
\hline & & & & & & 1801 & 240 & 421 & & \\
\hline $321 \mathrm{~T}$ & 60 & IIIB & E5 & $\mathrm{AGC}(\mathrm{T} \rightarrow \mathrm{A}) \mathrm{GTG}$ & $145 \mathrm{~L} \rightarrow \mathrm{Q}$ & + & + & + & Missense & Heterozygous \\
\hline $322 \mathrm{~T}$ & 73 & IIIB & E6 & $\mathrm{CTT}(\mathrm{A} \rightarrow \mathrm{T}) \mathrm{TCC}$ & $195 \mathrm{I} \rightarrow \mathrm{F}$ & + & + & - & Missense & Hemizygous \\
\hline $323 \mathrm{~T}$ & 63 & I & E7 & $\mathrm{AAC}(\mathrm{C} \rightarrow \mathrm{T}) \mathrm{GGA}$ & $248 \mathrm{R} \rightarrow \mathrm{W}$ & + & + & - & Missense & Hemizygous \\
\hline $329 \mathrm{~T}$ & 66 & I & E5 & $\mathrm{GGC}(\mathrm{G} \rightarrow \mathrm{A}) \mathrm{CTG}$ & $175 \mathrm{R} \rightarrow \mathrm{H}$ & + & + & + & Missense & Heterozygous \\
\hline $340 \mathrm{~T}$ & 64 & $\mathbf{I}$ & E5 & GAT(A)GCG & $1851 \mathrm{bp}$ deletion & - & - & - & Deletion/frameshift & Hemizygous \\
\hline $345 \mathrm{~T}^{*}$ & 71 & IIB & I4 & $\mathrm{aca}(\mathrm{g} \rightarrow \mathrm{c})$ TAC & Last $3^{\prime}$ base splice junction & + & + & + & Splice site alteration & Hemizygous \\
\hline $346 \mathrm{~T}$ & 72 & I & E5 & $\mathrm{CCA}(\mathrm{G} \rightarrow \mathrm{A}) \mathrm{GAG}$ & $179 \mathrm{H} \rightarrow \mathrm{Q}$ & + & + & + & Missense & Hemizygous \\
\hline $347 \mathrm{~T}$ & 68 & I & E7 & $\mathrm{CAT}(\mathrm{G} \rightarrow \mathrm{A}) \mathrm{AAC}$ & $246 \mathrm{M} \rightarrow \mathrm{I}$ & - & - & - & Missense & Hemizygous \\
\hline $350 \mathrm{~T}$ & 83 & IIA & E8 & $\mathrm{TGC}(\mathrm{G} \rightarrow \mathrm{A}) \mathrm{TGT}$ & $273 \mathrm{R} \rightarrow \mathrm{H}$ & + & + & + & Missense & Hemizygous \\
\hline $351 \mathrm{~T}$ & 53 & IIB & E6 & $\mathrm{GAC}(\mathrm{A} \rightarrow \mathrm{T}) \mathrm{GAA}$ & $209 \mathrm{R} \rightarrow$ stop & - & - & - & Nonsense & Hemizygous \\
\hline $363 \mathrm{~T}$ & 50 & IIA & E7 & $\mathrm{ACC}(\mathrm{G} \rightarrow \mathrm{A}) \mathrm{GAG}$ & $248 \mathrm{R} \rightarrow \mathrm{Q}$ & + & + & + & Missense & Heterozygous \\
\hline $366 \mathrm{~T}$ & 69 & IIB & E8 & $\mathrm{GAG}(\mathrm{G} \rightarrow \mathrm{A}) \mathrm{AAG}$ & $286 \mathrm{E} \rightarrow \mathrm{K}$ & + & + & + & Missense & Hemizygous \\
\hline $371 \mathrm{~T}$ & 51 & I & E5 & TGCCCCC(C)AC & 176-178 1-bp insertion & - & - & - & Insertion/frameshift & Hemizygous \\
\hline $375 \mathrm{~T}$ & 57 & IIA & E8 & $\mathrm{GTG}(\mathrm{C} \rightarrow \mathrm{T}) \mathrm{GTG}$ & $273 \mathrm{R} \rightarrow \mathrm{C}$ & + & + & + & Missense & Heterozygous \\
\hline
\end{tabular}

* The $3^{\prime}$-splice site is determined by a scanning mechanism which searches for the first AG located $3^{\prime}$ of the lariat branch point (29). The next available AG dinucleotide occurs after a pyrimidine rich sequence 21 nucleotides downstream ( $5^{\prime}$-TACTCCCCTGCCCTCAACAAGATG-3'). If splicing occurred with this site, a 7-amino acid inframe deletion would result. The previous inframe deletions analyzed are associated with immunohistochemical nuclear reactivity (17).

Xenobiotics which target primarily A:T base pairs can cause $\mathrm{A}: \mathrm{T} \rightarrow \mathrm{T}: \mathrm{A}$ changes. For example, ethylene oxide, an industrial chemical produced in large volumes and also formed in vivo after metabolic conversion of ethene, causes A:T $\rightarrow T: A$ transversions in the hypoxanthine-guanine phosphoribosyltransferase gene ( 5 of 13 induced single base substitutions) (28). Based on comparison of p53 mutations in breast cancers in different populations, we previously suggested that there are differences in factors contributing to breast carcinogenesis among racially and geographically diverse groups $(11,17,18)$. Coles et al. (19) and Biggs et al. (25) also have speculated that exogenous genotoxic factors may play a role in mammary carcinogenesis based on differences in patterns of mutations in the p53 gene in breast, lung, and colon cancer and in comparison with the pattern in the factor IX gene. Assuming genetic factors determining DNA replication and repair are similar among Austrian, other European, and U.S. Midwestern white women, the differences in frequency of microdeletions and in specific types of transitions and transversions among the different populations are compatible with the possibility that exposure to environmental toxins contributes to mammary carcinogenesis to different extents in these groups. Additional mutations in the Austrian population are desirable in order to confirm the apparent excess of $\mathrm{A}: \mathrm{T} \rightarrow \mathrm{T}: \mathrm{A}$ transversions in this cohort.

We recently found a strong association between $\mathrm{p} 53$ mutation and shorter time to recurrence and a shorter survival in

Table II. Mutations in Exons 5-9 of the p53 Gene in Breast Cancer from Various Caucasian Populations (in \%)

\begin{tabular}{|c|c|c|c|c|c|c|c|c|c|}
\hline \multirow[b]{2}{*}{ Origin of patients } & \multirow{2}{*}{$\begin{array}{l}\text { No. of mutations } \\
\text { (percentage of } \\
\text { tumors) }\end{array}$} & \multirow{2}{*}{$\begin{array}{l}\text { Deletion/ } \\
\text { insertion }\end{array}$} & \multicolumn{3}{|c|}{ Transitions } & \multicolumn{4}{|c|}{ Transversions } \\
\hline & & & $\mathrm{G}: \mathrm{C} \rightarrow \mathrm{A}: \mathrm{T}$ CpG & $\mathrm{G}: \mathrm{C} \rightarrow \mathrm{A}: \mathrm{T}$ non-CpG & $A: T \rightarrow G: C$ & $\mathrm{G}: \mathrm{C} \rightarrow \mathrm{C}: \mathrm{G}$ & $\mathrm{G}: \mathrm{C} \rightarrow \mathrm{T}: \mathrm{A}$ & $A: T \rightarrow C: G$ & $A: T \rightarrow T: A$ \\
\hline Austrian & $14(23.3)$ & 14.3 & 35.7 & 14.3 & 0 & 7.1 & 0 & 0 & 28.6 \\
\hline Midwest U.S.* & $18(34.0)$ & 38.8 & 27.8 & 5.5 & 0 & 11.1 & 0 & 5.5 & 11.1 \\
\hline Scotland ${ }^{\ddagger}$ & $41(29.9)$ & 7.3 & 14.6 & 17.0 & 9.7 & 9.7 & 22.0 & 14.6 & 4.9 \\
\hline France $^{8}$ & $18(18.8)$ & 11.1 & 22.2 & 11.1 & 0 & 11.1 & 22.2 & 11.1 & 11.1 \\
\hline Iceland" & $15(15.5)$ & 20.0 & 40.0 & 20.0 & 6.7 & 0 & 13.3 & 0 & 0 \\
\hline Norway' & $35(20.0)$ & 17.1 & 28.6 & 20.0 & 11.4 & 2.9 & 11.4 & 8.6 & 0 \\
\hline \multicolumn{10}{|l|}{ European } \\
\hline pooled** & $109(21.0)$ & 12.8 & 23.8 & 17.4 & 8.3 & 6.4 & 17.4 & 10.1 & 3.7 \\
\hline
\end{tabular}

The mutations were obtained from the following sources (the $P$ values in parentheses are the result of comparisons with the Austrian pattern of mutation by a Fisher Exact Test): ${ }^{*}$ Saitoh et al. $1994(17 ; P=0.31)$; ${ }^{\ddagger}$ Coles et al. $1992(19 ; P=0.028) ;{ }^{8}$ Mazars et al. $1992(30 ; P=0.39)$; " Thorlacius et al. 1993 (31; $P=0.10)$; ' Andersen et al. $1993(32 ; P=0.04)$; ${ }^{* *}$ Because all pairwise comparisons of the patterns of mutation in the cohorts from Scotland, France, Iceland, and Norway were not statistically significant, the data of the different European groups were pooled $(P=0.027)$. 
breast cancers in U.S. Midwestern white women after adjustment for ER, PR, and nodal status (17). Several other groups have reported that p53 mutation, frequently assessed indirectly on the basis of immunohistochemical overexpression of p53 protein, is correlated with poor prognosis (reviewed in reference $4)$. However, in the present study there were only a few recurrences of breast cancer ( 8 of $60 ; 13.3 \%$ ), none of the Austrian women died of their disease and neither the presence of a p53 mutation nor ER/PR status and lymph node status correlated with prognosis as assessed by disease free survival with a median follow-up of two years. The low recurrence and death rate in Austrians compared to the Midwestern U.S. group may be related to differences in the tumor stages between these two groups as assessed by comparison of all stages according to the American Joint Committee on Cancer (I, IIA, IIB, IIIA, IIIB, IV - Fisher Exact Test; $2 \times 6$ table; $P=0.028$ ). Pairwise comparisons of the specific stages revealed, that the main difference between the Austrian and the U.S. Midwestern groups was a greater frequency of stage I tumors $(23$ of $60 ; 38.3 \%)$ in the Austrian cohort compared to the U.S. Caucasian women ( 6 of $53 ; 11.3 \%)$. The Caucasian population had many more stage II tumors, whereas the frequency of advanced stage III and IV breast cancers was nearly the same. In our U.S. sample with an 18-mo follow-up, 7 of 18 patients with p53 mutation died whereas none of the 35 patients without p53 mutation died. Longer follow-up and larger cohorts are necessary to assess the value of p53 mutation analysis as a prognostic indicator in stages I and II breast cancer in European and U.S. populations.

\section{Acknowledgments}

This work was supported by a grant, R01-CA56881 (J.S. Kovach), a grant by the Dr. Mildred Scheel Foundation for Cancer Research (A. Hartmann, H. Blaszyk), and CA15086 (Molecular Probe Core of the Mayo Comprehensive Cancer Center), from the National Cancer Institute, NIH, DHHS, Bethesda, MD.

\section{References}

1. Sommer, S. S. 1990. Mutagen test. Nature (Lond.). 346:22-23.

2. Jones, P. A., J. D. Buckley, B. E. Henderson, R. K. Ross, and M. C. Pike. 1991. From gene to carcinogen: a rapidly evolving field in molecular epidemiology. Cancer Res. 51:3617-3620.

3. Shields, P. G., and C. C. Harris. 1991. Molecular epidemiology and the genetics of environmental cancer. JAMA. 266:681-687.

4. Harris, C. C., and M. Hollstein. 1993. Clinical implications of the p53 tumor-suppressor gene. N. Engl. J. Med. 329:1318-1327.

5. Chiba, I., I. Takahashi, M. M. Nau, D. D'Amico, D. T. Curiel, T. Mitsudomi, D. L. Buchhagen, D. Carbone, S. Piantadosi, H. Koga, P. T. Reissman, D. J. Slamon, E. C. Holmes, and J. D. Minna. 1990. Mutations in the p53 gene are frequent in primary, resected non-small cell lung cancers. Oncogene. 5:10631610.

6. Bressac, B., M. Kew, J. Wands, and M. Ozturk. 1991. Selective G to T mutations of p53 in hepatocellular carcinoma from Southern Africa. Nature (Lond.). 350:429-431.

7. Hsu, I. C., R. A. Metcalf, T. Sun, J. A. Welsh, N. J. Wang, and C. C. Harris. 1991. Mutational hotspot in the p53 gene in human hepatocellular carcinoma. Nature (Lond.). 350:427-428.

8. Brash, D. E., J. A. Rudolph, J. A. Simon, A. Lin, G. J. McKenna, H. P. Baden, A. J. Halperin, and J. Poten. 1991. A role for sunlight in skin cancer: UV induced p53 mutations in squamous cell carcinoma. Proc. Natl. Acad. Sci. USA. 88:10124-10128.
9. Molés, J. P., C. Moyret, B. Buillot, B. Jeanteur, J. J. Guihou, C. Theillet and N. Basset-Sequin. 1993. p53 gene mutations in human epithelial skin cancers. Oncogene. 8:583-588.

10. Kovach, J. S., R. M. McGovern, J. D. Cassady, S. K. Swanson, L. E. Wold, B. Vogelstein, and S. S. Sommer. 1991. Direct sequencing from touch preparations of human carcinomas: analysis of $\mathrm{p} 53$ mutations in breast carcinomas. J N C I. 83:1004-1009.

11. Sommer, S. S., J. Cunningham, R. M. McGovern, S. Saitoh, J. J. Schroeder, L. E. Wold, and J. S. Kovach. 1992. Pattern of p53 mutations in breast cancers of the Midwestern United States. J N C I. 84:246-252.

12. Coleman, M. P., J. Esteve, P. Damiecki, A. Arslan, and H. Renard. 1993 Trends in Cancer Incidence and Mortality. IARC Scientific Publications \#121, Lyon.

13. Boring, C. C., T. S. Squires, and T. Tong. 1993. CA: A Cancer Journal for Clinicians. 43:7-26.

14. Stemmermann, G. N. 1991. The pathology of breast cancer in Japanese women compared to other ethnic groups: a review. Breast Cancer Res. Treat. 18:S67-S72.

15. Shimizu, H., R. K. Ross, L. Bernstein, R. Yatani, B. E. Henderson, and T. M. Mack. 1991. Cancers of the prostate and breast among Japanese and white immigrants in Los Angeles County. Br. J. Cancer. 63:963-966.

16. Ziegler, R. G., R. N. Hoover, M. C. Pike, A. Hildesheim, A. M. Y. Nomura, D. W. West, A. H. Wu-Williams, L. N. Kolonel, P. L. Horn-Ross, J. F Rosenthal, and M. B. Hyer. 1993. Migration patterns and breast cancer risk in Asian-American women. J. Natl. Cancer. Inst. 85:1819-1827.

17. Saitoh, S., J. Cunningham, E. M. G. De Vries, R. M. McGovern, J. J. Schroeder, A. Hartmann, H. Blaszyk, L. E. Wold, D. Schaid, S. S. Sommer, and J. S. Kovach. 1994. p53 gene mutations in breast cancers in Midwestern U.S women: Null as well as missense-type mutations are associated with poor prognosis. Oncogene. In press.

18. Blaszyk, H., C. B. Vaughn, A. Hartmann, R. M. McGovern, J. J. Schroeder, J. Cunningham, D. Schaid, S. S. Sommer, and J. S. Kovach. 1994. Novel pattern of $\mathrm{p} 53$ gene mutations in an American black cohort with high mortality from breast cancer. Lancet. 343:1195-1197.

19. Coles, C., A. Condie, U. Chetty, C. M. Steel, H. J. Evans, and J. Prosser. 1992. p53 mutations in breast cancer. Cancer Res. 52:5291-5298.

20. Stoflet, E. S., D. D. Koeberl, G. Sarkar, and S. S. Sommer. 1988. Genomic amplification with transcript sequencing. Science (Wash. DC). 239:491-494

21. Sarkar G., H.-S. Yoon, and S. S. Sommer. 1992. Dideoxyfingerprinting $(\mathrm{ddF})$ : A rapid and efficient screen for the presence of mutations. Genomics. 13:441-443.

22. Kaplan, E. L., and P. Meier. 1958. Nonparametric estimation from incomplete observations. J. Am. Stat. Assoc. 53:456-481.

23. StatXact, ver 2.0 Cytel Software Corporation, Cambridge, MA, 1991.

24. Borresen, A.-L., T. I. Andersen, J. Garber, N. Barbier-Piraux, S. Thorlacius, J. Eyf jörd, L. Ottestad, B. Smith-Sorensen, E. Hovig, D. Malkin, and S. H. Friend. 1992. Screening for germ line TP53 mutations in breast cancer patients. Cancer Res. 52:3234-3236.

25. Biggs, P. J., W. Warren, S. Vernitt, and M. R. Stratton. 1993. Does a genotoxic carcinogen contribute to human breast cancer? The value of mutational spectra in unravelling the etiology of cancers. Mutagenesis. 8:275-283.

26. Sommer S. S. 1992. Assessing the underlying pattern of human germline mutations: Lessons from the factor IX gene. FASEB (Fed. Am. Soc. Exp. Biol.) J. 6:2767-2774.

27. Gostout, B., E. Vielhaber, R. P. Ketterling, H.-S. Yoon, C. D. K. Bottema, C. K. Kasper, M. A. Koerper, and S. S. Sommer. 1993. Germline mutations in the factor IX gene: A comparison of the pattern in Caucasians and non-Caucasians. Hum. Mol. Genet. 2:293-298.

28. Bastlova, T., B. Andersson, B. Lambert, and A. Kolman. 1993. Molecular analysis of ethylene oxide-induced mutations at the HPRT locus in human diploid fibroblasts. Mut. Res. 287:283-292.

29. Smith, C. W. J., E. B. Porro, J. G. Patton, and B. Nadal-Ginard. 1989. Scanning from an independently specified branch point defines the $3^{\prime}$ splice site of mammalian introns. Nature (Lond.). 342:243-247.

30. Mazars, R., L. Spinardi, M. BenCheikh, J. Simony-Lafontaine, P. Jeanteur and C. Theillet. 1992. p53 mutations occur in aggressive breast cancer. Cancer Res. 52:3918-3923.

31. Thorlacius, S., A.-L. Borresen, and J. E. Eyf jord. 1993. Somatic p53 mutations in human breast carcinomas in an Icelandic population: a prognostic factor. Cancer Res. 53:1637-1641.

32. Andersen, T. I., R. Holm, J. M. Nesland, K. R. Heimdal, L. Ottestad, and A.-L. Borresen. 1993. Prognostic significance of TP53 alterations in breast carcinoma. Br. J. Cancer. 68(3):540-548. 